\title{
FUNDAMENTOS CONTEMPORÂNEOS DA IMPOSIÇÃO TRIBUTÁRIA E A FUNÇÃO SOCIAL DO TRIBUTO
}

\section{CONTEMPORARY FOUNDATIONS OF TAX IMPOSITION AND THE SOCIAL FUNCTION OF TAX}

\section{Clovis Demarchi ${ }^{1}$ Tomás José Medeiros Lima}

Resumo: A percepção científica e social sobre os fundamentos da imposição tributária tem acompanhado as alterações do exercício do poder de tributar durante a história. Para formular um esboço de como se materializa, na atualidade, em tempos de reformas na legislação tributária, é necessário revisitar o comportamento histórico do instituto, além de analisar o arcabouço jurídico que atualmente rege o poder tributário. Nesse sentido, o presente estudo aborda a temática da fundamentação contemporânea da imposição tributária, focando especialmente nos seus aspectos controvertidos, por meio da revisão da literatura das principais teorias apresentadas pela doutrina tradicional. Para alcançar o objetivo, são analisados temas, como Ciência do Direito, Direito Positivo, poder tributário, imposição tributária. O resultado alcançado é que o poder tributário se revela como principal mecanismo de satisfação do Estado de arrecadar recursos financeiros, mas que tem prevalecido a percepção de

1. Doutor e Mestre em Ciência Jurídica pela Universidade do Vale do Itajaí (UNIVALI), Itajaí, SC, Brasil. Professor no Programa de Pós-Graduação Stricto Sensu em Ciência Jurídica - UNIVALI, Itajaí, SC, Brasil. Endereço eletrônico: demarchi@univali.br. ORCID: https://orcid.org/0000-0003-08530818 .

2. Mestrando em Ciência Jurídica da Univali-SC, em convênio com a Faculdade Católica de Rondônia. Especialista em Direito Processual Civil pela Faculdade de Administração e Negócios de Sergipe. Graduado em Direito pela Universidade Federal de Sergipe. Procurador de Estado de Rondônia, com lotação na Procuradoria Fiscal. E-mail: tomas.adv@gmail.com. ORCID: https://orcid.org/0000-0002-5717-4357. 
que a imposição tributária se encontra inserida numa relação de poder, importando na sua rejeição. Foi desenvolvido o trabalho sob o método indutivo, sendo operacionalizado com as técnicas do referente, da categoria e do conceito operacional, mediante pesquisa bibliográfica.

Palavras-chave: Poder tributário. Imposição tributária. Função social do tributo.

Abstract: The scientific and social perception of the fundamentals of taxation has accompanied changes in the exercise of the power to tax throughout history. For formulating an outline of how it materializes today, especially in times of reforms in tax legislation, it is necessary to revisit the historical behavior of the institute, in addition to analyzing the legal framework that currently governs tax power. In this sense, the present study addresses the theme of contemporary reasoning of taxation, focusing especially on its controversial aspects, through a literature review of the main theories presented by traditional doctrine. For achieving this objective, topics such as Science of Law, Positive Law, tax power, tax imposition are analyzed. The result achieved is that the tax power is revealed as the main mechanism of satisfaction of State to raise financial resources, but the perception that the tax imposition is inserted in a power relation has been prevailed, implying its rejection. The work was developed under the inductive method, being operationalized with the techniques of the referent, the category and the operational concept, through bibliographic research.

Keywords: Tax power. Tax imposition. Social function of the tax.

\section{INTRODUÇÃO}

O presente artigo científico se centra no escopo de analisar os fundamentos da imposição tributária na atualidade e apresentar alguns elementos da função social dos tributos, dada a relevância da questão em tempos de reforma tributária, bem como identificar como a atividade exacional é (ou como se supõe que deveria ser) percebida pelo ente tributante e pelo contribuinte.

No Brasil contemporâneo, atravessa-se um momento notadamente marcado pelo desejo de mudanças constitucionais e infraconstitucio- 
nais na legislação tributária, oportunidade na qual é propício repensar os fundamentos da imposição tributária, refletindo sobre onde irá repousar a atividade legislativa de reforma do ordenamento fiscal.

Tal situação de mudança é costumeira e acontece com certa frequência, visto que qualquer sistema tributário precisa ser constantemente revisado, sendo natural que sejam repensadas novas soluções que permitam o seu aperfeiçoamento, no sentido de melhorar a eficiência e a justiça fiscal.

Há necessidade de uma reforma profunda na percepção do poder de tributar, tanto pelo Fisco, no sentido de compreender a necessidade de se promover uma política tributária mais eficiente e simplificada, como pelo próprio contribuinte, a quem cabe enxergar a sua sujeição ao tributo como um dos caminhos que viabiliza ao Estado concretizar os interesses públicos.

Pois, se ficar clara a aplicação desses recursos que são recolhidos, o cidadão entenderá que pagar tributos não é uma simples obrigação como cidadão, mas a sua contribuição para a cidadania, visto que a arrecadação dos tributos é necessária e fundamental para o desenvolvimento econômico e social de todos.

O texto apresenta a discussão e fundamentação do tema em quatro momentos específicos, além da introdução e das concussões. Trata da Disciplina Jurídica do poder tributário em que se analisa o poder de tributar; em momento seguinte, dispõe sobre a imposição tributária e sua regulamentação no ordenamento jurídico vigente, momento em que se analisa a necessidade de o Estado angariar recursos para a administração da sociedade; no seguinte, trata dos fundamentos contemporâneos da imposição tributária em que há a preocupação do Estado em arrecadar, mas também de tornar a sociedade ciente da necessidade de contribuir com os tributos; e, no próximo momento, trata sobre a função social do tributo e a cidadania.

Ressalta-se que, após a análise da necessidade de a sociedade estar ciente da importância dos tributos, observa-se que a correta aplicação das receitas caracteriza a função social dos tributos. $\mathrm{O}$ conhecimento por parte da sociedade da engrenagem tributária, por mais complexo 
que seja o sistema, é fundamental para que os contribuintes entendam e saibam o porquê e para que estão contribuindo.

Quanto à metodologia adotada, seguiu-se o magistério de Pasold (2018), utilizando-se o método indutivo, sendo operacionalizado com as técnicas do referente, da categoria e do conceito operacional, mediante pesquisa bibliográfica.

\section{DISCIPLINA JURÍDICA DO PODER TRIBUTÁRIO}

Um dos debates mais acalorados da Ciência Jurídica se centra no estudo da dicotomia entre o Direito Natural e o Direito Positivo. Na dogmática tributarista, todavia, essa discussão perde terreno, na medida em que, contemporaneamente, a positivação é condição de validade da norma tributária.

Segundo Nogueira (1990, p. 122), tratando-se do Estado de Direito Constitucional, a possibilidade ou o exercício do poder de tributar está em primeiro lugar, submetido à disciplina da Constituição, dentro da qual, explícita ou implicitamente, se encontram as bases do Direito Constitucional Tributário Positivo.

Cabe apenas ressalvar que isso não significa ser facultado ao legislador edificar um ordenamento jurídicos e valendo unicamente das regras do Direito Positivo, afastado das "normas naturais" da realidade social a qual se pretende regular.

Nesse sentido, Martins (2010, p. 369-370) propõe uma visão conciliadora de tais ramos do Direito na formação do Estado, verificando que a conformidade do plano jurídico formal somente estará perfeitamente delineada se regida pelo imperativo lógico das leis naturais, justificando que o Estado ideal apenas existe "[...] no plano formal, se subordina à lei produzida por quem detém o poder, por livre e universal escolha, e, no plano real, promove a conjunção das leis positivas com as leis naturais".

Dito isso e avançando para além de tal dissenso, que não é objeto deste apertado estudo, é forçoso reconhecer que a temática da normatização tributária atualmente se insere, invariavelmente, no campo do 
Direito Positivo, uma vez que a ela se encontra estabelecida no seio do Estado de Direito.

Por isso, é preciso retroceder às origens históricas dessa atividade normativa para compreender como o poder tributário se exprime na atualidade, ressalvando-se novamente que o Direito Tributário se exterioriza por meio da norma tributária positivada.

Coêlho (2020, p.4) relembra que, há cerca de três séculos apenas, o jus tributandi e o jus puniendi eram atributos do poder sem limites dos governantes, o que foi gradualmente sendo restringido por meio de princípios impostos: capacidade contributiva, igualdade, legalidade, tipicidade, proibição do confisco, irretroatividade entre outros.

O mesmo autor (2020, p. 13) coloca que o Direito surge no meio da sociedade e se desenvolve nela como técnica de disciplinação e controle social, restando formalizado por meio da linguagem escrita ou oral e se assemelhando às prescrições, tratando-se de ordens respaldadas por ameaças.

Martins (2005, p. 226) dispõe que foi pelo Iluminismo Cultural e pelo Positivismo Filosófico do século XVIII que a Ciência Jurídica foi decisivamente influenciada, dissociando-se de todos os valores pré e meta-jurídicos de que antes era impregnada, trazendo "[...] o princípio de que a razão e a humanidade eram os valores supremos e só aquilo que estivesse no mundo cognoscível representaria a realidade a ser investigada [...]".

O referido tributarista pontua que tais correntes filosófica e cultural, respectivamente, terminaram por influenciar o pragmatismo político dos governos do século XIX e, no plano jurídico, foram o arrimo para a construção da teoria da Ciência Pura do Direito de Hans Kelsen, em que restou estabelecido o próprio campo de pesquisa desta, exclusivamente na norma jurídica positivada, extirpando toda a contaminação de outras ciências. Alude ainda que, segundo tal teoria, devem ser ignorados pelo jurista a Economia, a História, a Sociologia e a Política, cabendo ao Estado o poder de impor a norma e fazê-la ser obedecida, independentemente de ser justa ou injusta. 
Assim, é no arranjo piramidal do ordenamento jurídico proposto por Kelsen, no qual a Constituição se posiciona hierarquicamente acima das normas infraconstitucionais, que o Direito Positivo se estabelece como mecanismo de elaboração e construção da Ciência do Direito.

Sobre a Ciência do Direito, Ferrajoli (2015, p. 36) apresenta sua tese no sentido de que a formulação em normas de direito positivo das normas sobre a produção jurídica é a técnica pela qual foram, historicamente, democratizadas as regras que disciplinam tanto a forma de produção quanto a substância do direito produzido.

Importa observar que tais conceitos de "Ciência do Direito" e o "Direito Positivo" não se confundem. Nesse sentido, Carvalho (2019, p. 41) infere haver uma relação nivelada entre estes, dispondo que a Ciência do Direito é uma sobre linguagem (ou linguagem de sobrenível) com relação ao Direito Positivo, estando acima e discorrendo sobre ela, transmitindo notícias de sua compostura como sistema empírico.

Nesse tocante, basilar apresentar as lições de Carvalho (2019, p. 41) sobre tal distinção:

Por isso, não é demais enfatizar que o direito positivo é o complexo de normas jurídicas válidas num dado país. À Ciência do Direito cabe descrever esse enredo normativo, ordenando-o, declarando sua hierarquia, exibindo as formas lógicas que governam o entrelaçamento das várias unidades do sistema e oferecendo seus conteúdos de significação.

Cabe ainda uma relevante constatação histórica de Martins (2005, p. 228), no sentido de que o positivismo jurídico alicerçou as pretensões do nazismo e do fascismo, já que estes adotaram a teoria kelseniana, restando notável o papel de plano de flagramento da $2^{\mathrm{a}}$ Guerra Mundial, “[...] pois o Direito deixou de buscar a ordem social justa, passando a ser apenas justificado pelo poder coercitivo exercitado em nome do Estado - representando ou não o povo - para impor a obediência à norma e a sanção pelo seu descumprimento".

Por essa razão, impende alertar os perigos de o Estado se valer do poder de tributar centrado unicamente no Direito Positivo, ignorando 
os demais ramos científicos, ou mesmo as "leis naturais" que norteiam o que é bom, moral e justo.

Nessa linha, Machado (2018, p. 142-143) critica a influência do pensamento positivista no ramo tributário, alegando que nele há a equivocada compreensão de que o Direito prescinde da ética, observando que sob tal paradigma o Fisco não se preocupa com o conteúdo ético das normas de tributação, ou mesmo em promover uma tributação justa, desejando somente aumentar o volume dos recursos financeiros arrecadados e se valendo, para tanto, da edição desenfreada de normas, o que torna impraticável o conhecimento seguro do conteúdo destas pelos contribuintes. Diante desse quadro, o autor é levado a propor uma fundamentação ética da norma, que realoca o Direito em sua posição de especial instrumento da harmonia social.

Por sua vez, Carvalho (2019, p. 168-169) sugere a aplicação da doutrina da autopoiese, que supera as visões de sistemas abertos ou fechados, propondo uma compreensão intermediária e sistemática do Direito Positivo, que consiste no seu fechamento no plano operacional, mas aberto em termos cognitivos. Segundo propõe, o Direito deve se comunicar com os outros subsistemas sociais, como economia, política, moral, religião etc., mas de forma exclusivamente cognoscitiva, devendo o sistema jurídico ser operado totalmente alheio a qualquer influxo do meio exterior, o que permite manter a sua autonomia.

A ressalva anterior é relevante para o estudo, porquanto, para se desenvolver uma adequada compreensão da imposição tributária no ordenamento jurídico, o jurista deve conhecer os demais fatores sociais sobre os quais aquela orbita, cuja percepção vai além do restrito conteúdo normativo indicado pela Ciência Pura do Direito.

\section{DA IMPOSIÇÃO TRIBUTÁRIA E SUA REGULAMENTAÇÃO NO ORDENAMENTO JURÍDICO VIGENTE}

Como visto no item anterior, o poder tributário se encontra delimitado no Estado de Direito à norma jurídica positivada. 
Coêlho (2020, p. 26) menciona que, nos tempos atuais, o poder de tributar é exercido por delegação do povo ao Estado Constitucional, uma vez que é produto da Assembleia Constituinte, expressão básica e fundamental da vontade coletiva, sendo que "a Constituição, estatuto fundante, cria juridicamente o Estado, determina-lhe a estrutura básica, institui poderes, fixa competências, discrimina e estatui os direitos e as garantias das pessoas, protegendo a sociedade civil”.

Desse exercício do poder tributário, nasce a imposição tributária, definida por Martins (2010, p. 15) como decorrência das necessidades do Estado em gerar recursos para sua manutenção e a dos governos que o administram, cujo fenômeno é oriundo "[...] no campo da Economia, sendo reavaliado na área de Finanças Públicas e normatizado pela Ciência do Direito", consubstanciado na tríplice fato-valor-norma (Economia-Finanças Públicas-Direito).

Em outra obra do mesmo autor (2005, p. 280), é explicitado em mais detalhes essa percepção:

O aspecto valorativo do "substractum" econômico, que determina por desaguar em solução de regulação tributária ou meramente administrativa, visto pelo prisma de uma teoria tripartida do direito de conteúdo unitário, traz como consequência do ato de valorara escolha definitiva da solução normativa, que, quando adentrando o campo tributário, necessita instrumental mais abrangente de percepção e mais limitado de execução [...].

Adentrando na normatização, relembra Coêlho (2020, p. 26) que o poder de tributar, modernamente, é o campo predileto de labor do legislador constituinte, especialmente por duas razões: "A uma, porque o exercício da tributação é fundamental aos interesses do Estado, tanto para auferir as receitas necessárias à realização de seus fins, sempre crescentes, quanto para utilizar o tributo como instrumento extrafiscal $[\ldots]^{\prime \prime}$.

Na mesma linha, Martins (2010, p. 375) evidencia que a imposição tributária abrange as facetas fiscal, parafiscal e extrafiscal, aduzindo que, qualquer que seja o campo próprio de ação e a finalidade da receita obtida ou desenvolvimento estipulado, “[...] o instrumental jurídico 
existente visualiza essa relação de índole econômica, de participação em determinadas atividades, mesmo que a título de paralelo desenvolvimento social".

Em continuidade ao estudo, Nogueira (1990, p. 122) leciona que cabe à Constituição disciplinar o exercício do poder de tributar, bem como "[...] catalogar, outorgar e distribuir competências tributárias, delimitá-las, classificar os tributos, dispor sobre sua partilha e arrecadações, impedir conflitos de competências e garantir o status do cidadão contribuinte".

No caso brasileiro, Melo (2010, p. 9) recorda que é por meio desses recursos que o Brasil atinge seus objetivos fundamentais, dispostos no art. $1^{\mathrm{o}}, \S 3^{\circ}$, da Constituição Federal, “[...] consistentes na construção de uma sociedade livre, justa e solidária, no desenvolvimento nacional, na erradicação da pobreza e marginalização, na redução das desigualdades sociais e regionais, bem como na promoção do bem-estar da coletividade", além das inúmeras e diversificadas atividades que os entes federados executam com tais recursos.

O mesmo autor (2010, p. 10) ainda informa que o sistema tributário é constituído por princípios e normas específicas, expressamente disciplinados em capítulo próprio da Constituição Federal (arts. 145 a 156) e em outros dispositivos esparsos (arts. $7^{\circ}, \mathrm{III} ; 195 ; 212, \S 5^{\circ} ; 239, \S \S 1^{\mathrm{o}}$; e $4^{\circ}$ e 240 ), sendo que, para examinar a matéria tributária, deve-se proceder "[...] a análise e a compreensão dos postulados e regras hauridas na Constituição, como lei fundamental e suprema do Estado, conferindo poderes, outorgando competências e estabelecendo os direitos e garantias individuais".

Coêlho (2016, p. 224) constata que, na Constituição pátria, há uma repartição das competências pela natureza dos fatos jurígenos, sendo que, para taxas e contribuições de melhoria, há uma renúncia expressa em relação a fatos jurígenos genéricos, enquanto, para os impostos, o constituinte não declina os fatos jurígenos autorizativos da instituição destes para os legisladores competentes.

É importante observar que a Constituição da República Federativa do Brasil de 1988, mais especificamente no seu $\S 1^{\circ}$ do art. 145 , dispõe 
de forma explícita sobre o princípio da capacidade contributiva aos impostos, como se observa:

Sempre que possível, os impostos terão caráter pessoal e serão graduados segundo a capacidade econômica do contribuinte, facultado à administração tributária, especialmente para conferir efetividade a esses objetivos, identificar, respeitados os direitos individuais e nos termos da lei, o patrimônio, os rendimentos e as atividades econômicas do contribuinte. (BRASIL, 2020).

Diante disso e nos dizeres de Machado (2019, p. 72), encontra-se hoje dominante na consciência jurídica universal como de observância obrigatória e "[...] deve ser visto como um princípio de justiça, e assim deve ser seguido pelo intérprete das normas tributárias em geral [...]”.

Nessa oportunidade, as lições de Coêlho (2016, p. 53) novamente se fazem necessárias, mais especificamente o seu apanhado doutrinário sobre o referido princípio:

Griziotti, há quase meio século, dizia que a capacidade contributiva indicava a potencialidade das pessoas de contribuir para os gastos públicos. Moschetti a conceituou como "aquela força econômica que deva julgar-se idônea a concorrer às despesas públicas", e não "qualquer manifestação de riqueza", acentuando assim a capacidade econômica real do contribuinte e, pois, personalizando o conceito. Aliomar Baleeiro avançou um pouco mais, fazendo surgir a capacidade contributiva como o elemento excedentário, sobrante, da capacidade econômica real do contribuinte; seria a "sua idoneidade econômica para suportar, sem sacrifício do indispensável à vida compatível com a dignidade humana, uma fração qualquer do custo total dos serviços públicos" [...].

Mais recentemente, Maria e Luchiezi Junior (2010, p. 17) sustentam que "este princípio integra o princípio da isonomia, que consiste em tratar os desiguais de modo desigual, podendo, assim, o tributo ser cobrado de acordo com as possibilidades de cada um", inferindo ainda que ele serve de alerta ao poder tributante, o qual não deve, ao propor as normas instituidoras dos tributos, suas alíquotas e bases de cálculo, atuar em sentido contrário. 
Por fim, Coêlho (2020, p. 51) conclui que, embora o dispositivo seja restrito aos impostos, a abrangência do princípio da capacidade contributiva é maior, traduzindo-se na aptidão de o indivíduo ser sujeito passivo de tributo se concorrer para os gastos públicos, sendo a capacidade contributiva " [...] o motor operacional do princípio da igualdade na esfera tributária, tendo o condão, por isso mesmo, de realizar o próprio valor justiça".

\section{FUNDAMENTOS CONTEMPORÂNEOS DA IMPOSIÇÃO TRIBUTÁRIA}

No Brasil contemporâneo, atravessa-se um momento notadamente marcado pelo desejo de mudanças constitucionais e infraconstitucionais na legislação tributária, oportunidade na qual é propício repensar os fundamentos da imposição tributária, refletindo sobre onde irá repousar a atividade legislativa de reforma do ordenamento fiscal.

Tal situação de mudança é costumeira e acontece com certa frequência, visto que qualquer sistema tributário precisa ser constantemente revisado, sendo natural que sejam repensadas novas soluções que permitam o seu aperfeiçoamento, no sentido de melhorar a eficiência e a justiça fiscal.

Antes de se tecer qualquer proposta que vise fundamentar o fenômeno da imposição tributária, é imperioso alertar que a manifestação do poder de tributar tem acompanhado os mais diversos arranjos sociais ao longo da História, motivo pelo qual a fluidez deste impacta diretamente na percepção do seu próprio conceito.

Nogueira (1990, p. 5-6) recorda que, desde os mais remotos tempos, verificam-se diversas denominações ao tributo, nas mais variadas línguas, sendo que já foram considerados como auxílios, doações, presentes, despojos de guerra, confiscos, contribuições arbitrárias (para os mais diversos fins) e, mais recentemente, como forma de obtenção de receita no sentido de "[...] proteger, com mais intensidade, não apenas os direitos individuais, mas, igualmente, os sociais". 
Em apertada recapitulação histórica, Greco (2012, p. 277) relembra que as raízes do tributo remontam ao uso da força na Antiguidade, atinente ao espólio da guerra exigido pelo vencedor ao vencido, passando pela investidura divina dada ao rei absolutista e ao seu poder ilimitado de tributar, apenas sendo possível observar alguma restrição de tal exercício no século XVII, por meio do Bill of Rights,e, em seguida, na Revolução Francesa, quando finalmente se consolidou uma verdadeira limitação à atividade exacional, por meio da instauração de uma fonte de legitimação racional normativa, qual seja, o Estado de Direito.

Nogueira (1990, p. 6) observa que, no Estado de Direito, os homens são governados pelo poder da lei e não pelo poder de outros homens, revelando-se uma proposição jurídica que trata igualmente todos que estejam na mesma situação, bem como se impondo como pessoa direitos e obrigações tanto aos particulares, quanto aos agentes do Estado e ao próprio Estado.

Quanto à Revolução Francesa, Martins (2005, p. 63-64) discorre que nela "[...] a predominância foi de o povo ser o verdadeiro destinatário do poder e das ações públicas, mas à luz, não de subordinação irrestrita, mas de participação efetiva", evidenciando-se o Estado como instituição teoricamente criada para a sociedade viver segundo sua livre escolha, nos padrões considerados ideais, seguindo o perfil delineado na sua lei suprema.

Schoueri $(2019$, p. 17,24/28) aponta que dificilmente hoje se encontra alguém que sustente qualquer outra forma de organização política que não seja o Estado, o qual pressupõe a busca de recursos financeiros para sua manutenção prioritariamente por meio de tributos, em processo gradativo histórico de substituição do modelo do "Estado de Polícia" pelo "Estado Fiscal", registrando ainda que este assumiu incialmente uma feição minimalista, sob inspiração do liberalismo para, em seguida, adotar uma função distributiva e alocativa, especialmente em seu viés indutor.

Assim, pode-se, contemporaneamente, indicar como principal fundamento da imposição tributária a necessidade de o Estado arrecadar recursos para o custeio da máquina pública, devendo se tratar de ins- 
tituto de aceitação voluntária e racional de tal condição pela própria sociedade, já que as atividades estatais visam à proteção e ao progresso social, estando, assim, inserido na noção de contrato social, que adere à ideia de civilização.

Além disso, Machado (2019, p. 69) recorda que hoje o poder tributário apresenta a função extrafiscal, em que é "[...] largamente utilizado com o objetivo de interferir na economia privada, estimulando atividades, setores econômicos ou regiões, desestimulando o consumo de certos bens e produzindo, finalmente, os efeitos mais diversos na economia”, além da função parafiscal, “[...] quando o seu objetivo é a arrecadação de recursos para o custeio de atividades que, em princípio, não integram funções próprias do Estado, mas este as desenvolve através de entidades específicas".

Em outra obra, Machado (2018, p.154) ainda distingue o interesse primário do Estado, na condição de titular do poder de tributar, justificando a edição da norma que institui ou aumenta o tributo para a obtenção dos meios necessários para à consecução dos seus fins (e que com ela se exaure), do interesse secundário ou instrumental do Estado, que pertence a este como pessoa, sujeito de direitos e obrigações na ordem jurídica, sendo igual ao interesse de qualquer outra pessoa na observância e na aplicação da norma.

Todavia, não se pode olvidar que, na prática, mesmo se estando ciente de todo o arrazoado que corrobora contemporaneamente a imposição tributária, registra-se ainda uma verdadeira admoestação social em suportar o referido ônus, magistralmente captada nas lições de Martins (2005, p. 79):

O tributo, que a sociedade jamais deseja pagar no nível em que os governos lhe cobram, é, talvez, a norma de rejeição social mais clara, mais nítida, no direito moderno, sempre suportada pela classe dominada em benefício da classe dominante. Pois que os homens não são iguais e os detentores do poder têm sempre mais direitos do que os pobres mortais não participantes, direta ou indiretamente, da direção do país. 
Assim, mesmo sendo possível visualizar todos os robustos fundamentos que justificam a atividade exacional do Estado, a percepção de que a ela está inserida numa relação de poder, enquadrada numa dinâmica injusta e conflitiva de classes, importa na sua clara rejeição.

Nos dizeres de Greco (2012, p. 284.), tal resistência da sociedade civil em face do fenômeno tributário necessita de evolução da própria experiência estatal, buscando o equilíbrio da relação fisco/contribuinte, no sentido de reconhecer que o seu núcleo finalístico se centra em conceber a tributação como exercício de uma atividade no desempenho de uma função instrumental de emancipação, superando o velho paradigma de dominação, "[...] pois isto implicará deslocar a sociedade civil de mera destinatária e submetida ao poder formal, para assumir o papel de protagonista positiva do direcionamento a imprimir a esta função”.

Na mesma linha, Paulsen $(2019$, p. 23) posiciona a tributação como instrumento da sociedade para a consecução dos seus próprios objetivos, não se tratando de uma submissão ao Estado, tampouco um mal necessário. Por isso, aduz não se sustentar mais “[...] os sentimentos de pura e simples rejeição à tributação. A figura de Robin Hood, que em algumas versões atacava os coletores de impostos para devolver o dinheiro ao povo, hoje já não faz sentido".

Ferraz Júnior (2014, p. 124) também enxerga essa conformação estatal de garantidor dos direitos sociais, aduzindo que "o estado social trouxe o problema da liberdade positiva, participativa, que não é um princípio a ser defendido, mas a ser realizado. Com a liberdade positiva, o direito à igualdade se transforma num direito a tornar-se igual nas condições de acesso à plena cidadania”.

Por sua vez, Melo (2010, p. 10) vislumbra no Direito Tributário uma efetiva dignidade constitucional em razão do peculiar e minucioso tratamento que lhe foi conferido pelo constituinte, "[...] o que tem o condão de revelar sua considerável importância no ordenamento jurídico, pela circunstância especial de, por um lado, representar fonte de receita para o Poder Público e, de outro, acarretar ingerência no patrimônio dos particulares". 
Seguindo a linha, Machado (2019, p. 24) sustenta que, pelo viés econômico, o tributo é o instrumento de que se tem valido a economia capitalista para sobreviver, na medida em que é por meio dele que o Estado realiza os seus fins sociais, inegavelmente se tornando, talvez, a única arma contra a estatização da economia.

Nogueira (1990, p. 129) acrescenta que, se fosse suprimido o tributo:

[...] acarretaria o fim da vida coletiva e a paralisação da vida individual, tendo em vista o elevado grau em que os serviços públicos, cujo funcionamento é assegurado pelo tributo, fazem parte da economia contemporânea. O tributo é, portanto, uma despesa individual tão essencial como a que é consagrada à habitação, à alimentação e ao vestuário.

Nesse escopo, Martins (2010, p. 375-376) aponta a necessidade de uma base de tributação mais elástica, visando reduzir a excessiva concentração de carga tributária sobre determinadas áreas, o que influenciaria a própria concepção de uma sociedade mais engajada no cumprimento de suas obrigações essenciais, dentre as quais, o pagamento do tributo legítimo e justo, levando a concluir da seguinte forma:

Este sentido de justiça da norma tributária é aquele de transcendental relevância para a compreensão da fenomenologia impositiva. Dele decorre a estruturação própria do sistema tributário, que terá de se adequar, em sua formulação obrigacional, com densidade maior na espécie sanção que aquela pertinente ao tributo, se mais distante se colocar dos princípios inerentes a uma desejada política fiscal.

De todo o apanhado, sobressai-se a necessidade de uma reforma profunda na percepção do poder de tributar, tanto pelo Fisco, no sentido de compreender a necessidade de se promover uma política tributária mais eficiente e simplificada, como pelo próprio contribuinte, a quem cabe enxergar a sua sujeição ao tributo como caminho que viabiliza o Estado a concretizar os interesses públicos. 


\section{FUNÇÃO SOCIAL DO TRIBUTO E CIDADANIA}

Como demostrando anteriormente, os tributos são fontes de recursos para o Estado, mas é importante lembrar que os tributos não devem

se resumir a apenas serem pagos pela sociedade. Melhor que isso é mostrar à sociedade como os recursos recolhidos são revertidos em melhorias para a qualidade de vida de todos, visando, assim, à garantia da dignidade humana por meio da efetivação dos direitos sociais. Conforme afirmam Liebl e Demarchi (2018,p.87), os direitos sociais garantem aos indivíduos as "condições imprescindíveis para o pleno gozo dos seus direitos" e, ao realizar esses direitos, o Estado necessita de um arcabouço financeiro para intervir socialmente e, dessa forma, reduzir as desigualdades sociais.

Dessa forma, ao se concretizar a função social do tributo e da justiça social tributária, concretiza-se a dignidade humana e se garante o mínimo existencial. Como se vive uma realidade em que isso não é perseguido como prioridade do governo brasileiro, está-se fadado a não se alcançar a dignidade da pessoa humana, assim como o mínimo existencial se encontra prejudicado.

Por outro lado, se ficar clara a aplicação desses recursos que são recolhidos, o cidadão entenderá que pagar tributos não é uma simples obrigação como cidadão, mas a sua contribuição para a cidadania, pois a arrecadação dos tributos é necessária e fundamental para o desenvolvimento econômico e social de todos. Nessa aplicação das receitas é que reside a função social dos tributos. A correta aplicação e o atendimento às necessidades da sociedade representam a contribuição de cada um para o conjunto da sociedade.

Diante da realidade atual em que se está repensando o sistema tributário nacional, impõe-se um processo de educação e conscientização fiscal em que tributador e contribuinte tenham o dever social de corretamente contribuir com a arrecadação e, também, corretamente aplicar o tributo arrecadado, garantindo, assim, uma justiça fiscal.

Nesse contexto, necessário que o cidadão participe mais do controle fiscal e social dos tributos, bem como da correta aplicação com a fina- 
lidade de atender às reais necessidades da sociedade e não aos interesses de quem administra ou governa o estado, pois, com a compreensão da natureza da tributação e das suas finalidades, pode-se entender e se aceitar algo compulsório.

Por isso, a necessidade de um processo de educação que resgate a noção de tributo como instrumento de obtenção do bem comum e de responsabilidade social. Para que isso aconteça, é necessário que a sociedade seja participante no processo de organização orçamentária e, consequentemente, beneficiária dos bens e serviços realizados.

É importante que a sociedade esteja ciente dos tributos como meio para a construção do bem comum, na qual todos devem participar da sua escolha, do monitoramento e dos benefícios. Assim como que economicamente todos estejam cientes e sejam sabedores da proposta e das ações tributárias, ou seja, que entendam por que determinados setores pagam mais que os outros, ou qual a razão de haver isenções e benefícios em vigor, ou, ainda, qual a necessidade de se abolir ou aumentar tributos. Por mais complexo que seja o sistema, deve ser facilitado para que os contribuintes entendam e saibam o porquê e para que estão contribuindo.

Com essa consciência e atuação, a questão fundamental que deve pairar sobre os tributos é que a equidade certamente se fará presente na prática. Ou seja, o governo, deixando claro o custo tributário e a forma como está distribuído entre os contribuintes, facilitará a sua aceitação e contribuição.

Até porque a dignidade como ofício, vinculada diretamente à noção de cidadania, conforme Demarchi e Fontana (2019, p. 575), tem o reconhecimento de deveres do indivíduo para com a comunidade, "deveres estes que, quando contidos na Constituição, são deveres fundamentais que podem e devem ser exigidos pela sociedade, como garantia de preservação do bem comum". Dessa forma, pagar impostos, conforme Demarchi e Fontana (2019, p. 575), contribui e possibilita a preservação da dignidade da pessoa humana, "mediante comunhão de esforços de todos, na medida da responsabilidade de cada indivíduo perante o próximo e para consigo mesmo". 
Quando isso está claro para a sociedade, há a percepção de que o sistema tributário é administrado, visando ao interesse de todos e com base em valores. Dessa forma, a imposição tributária não possui somente a face de arrecadadora de recursos e com a ideia de diminuir a capacidade econômica do contribuinte, mas se apresenta como o elo entre a captação e a construção do bem comum da sociedade.

\section{CONCLUSÃ̃}

Como disposto no início do trabalho, o objetivo principal do presente artigo científico foi analisar os fundamentos da imposição tributária na atualidade e verificar a sua função social neste momento, marcado notadamente por anseios de reforma tributária no Brasil, visando identificar como a atividade exacional é (ou como se supõe que deveria ser) percebida pelo ente tributante e pelo contribuinte.

Foi necessário, inicialmente, revisitar a disciplina atinente ao poder de tributar, passando pela conceituação e análise histórica da imposição tributária e sua regulamentação no ordenamento jurídico vigente.

Das constatações realizadas, observou-se que o poder de tributar tem se manifestado nos mais diversos arranjos sociais ao longo da História, motivo pelo qual a fluidez deste impacta diretamente na percepção do seu próprio conceito, mas, contemporaneamente, prevalece como seu principal fundamento a necessidade de o Estado arrecadar recursos financeiros para o custeio da máquina pública.

Foi também possível identificar que a percepção fática da sociedade deveria ser no sentido da aceitação voluntária e racional da imposição tributária, já que esta visa à proteção social e ao progresso. Todavia, tem prevalecido a percepção de que o tributo se encontra inserido numa relação de poder, enquadrada numa dinâmica injusta e conflitiva de classes, importando em sua rejeição.

Destaca-se como ideias fundamentais: a sujeição ao tributo é um caminho que viabiliza o Estado a concretizar os interesses públicos; os tributos não devem se resumir a apenas serem pagos pela sociedade; importante mostrar à sociedade como os recursos recolhidos são rever- 
tidos em melhorias para a qualidade de vida de todos; o cidadão deve estar ciente que pagar tributos não é uma simples obrigação como cidadão, mas a sua contribuição para a cidadania; na correta aplicação das receitas é que reside a função social dos tributos; por mais complexo que seja o sistema, deve ser facilitado para que os contribuintes entendam e saibam o porquê e para que estão contribuindo.

Finalmente, sugere-se uma reforma profunda no exercício do poder de tributar pelo Fisco, visando promover uma política tributária mais eficiente, simplificada e transparente para que o contribuinte esteja ciente e de acordo com a proposta que viabiliza o Estado a concretizar os interesses públicos e não simplesmente apresentar-se como um órgão de arrecadação e com aparência de querer diminuir o poder aquisitivo das pessoas.

\section{REFERÊNCIAS}

BRASIL. Constituição da república federativa do Brasil de 1988. Brasília: Senado Federal, 2020.

CARVAlHO, Paulo de Barros. Curso de direito tributário. 30. ed. São Paulo: Saraiva Educação, 2019.

COÊLHO, Sacha Calmon Navarro. Curso de direito tributário brasileiro. 17. ed. Rio de Janeiro: Forense, 2020.

COÊLHO, Sacha Calmon Navarro. O controle de constitucionalidade das leis e o poder de tributar na CF/1988. 4. ed. rev. e atual. Rio de Janeiro: Forense, 2016.

DEMARCHI, Clovis; FONTANA, Douglas Cristian. Deveres fundamentais e dignidade humana: uma perspectiva diferente. Revista Eletrônica Direito e Política, Programa de Pós-Graduação Stricto Sensu em Ciência Jurídica da UNIVALI, Itajaí, v.14, n.3, $3^{\circ}$ quadrimestre de 2019. Disponível em: https://siaiap32.univali.br/seer/index.php/rdp/article/view/15828/9083. 
FERRAJOLI, Luigi. A democracia através dos direitos: o constitucionalismo garantista como modelo teórico e como projeto político. Tradução de Alexander Araújo de Souza et al. São Paulo: Revista dos Tribunais, 2015.

FERRAZ JÚNIOR, Tércio Sampaio. O direito, entre o futuro e o passado. São Paulo: Noeses, 2014.

GRECO, Marco Aurélio. Do poder à função tributária. In: ALLEMAND, Luiz Cláudio Silva (coord.). Direito tributário: questões atuais. Brasília: OAB, Conselho Federal, Comissão Especial de Direito Tributário, 2012.

LIEBL, Helena; DEMARCHI, Clóvis. A efetividade da dignidade da pessoa humana através dos direitos sociais. Revista da ESMESC, Florianópolis, v.25, n.31, p. 85-106, 2018. Disponível em: https://revista. esmesc.org.br/re/article/view/185/159.

MACHADO, Hugo de Brito. Curso de direito tributário. 40. ed. rev. e atual. São Paulo: Malheiros, 2019.

MACHADO, Hugo de Brito. Normas gerais de direito tributário. São Paulo: Malheiros, 2018.

MACHADO, Hugo de Brito. Os princípios jurídicos da tributação na constituição de 1988. 6. ed. São Paulo: Malheiros, 2019.

MARIA, Elizabeth de Jesus; LUCHIEZI JUNIOR, Álvaro. Tributação no Brasil: em busca da justiça fiscal. Brasília: Sindifisconacional, 2010.

MARTINS, Ives Gandra da Silva. Curso de direito tributário. Coordenador Ives Gandra da Silva Martins. 12. ed. São Paulo: Saraiva, 2010.

MARTINS, Ives Gandra da Silva. Uma teoria do tributo. São Paulo: QuartierLatin, 2005.

MELO, José Eduardo Soares de. Curso de direito tributário. 9. ed. São Paulo: Dialética, 2010. 
NOGUEIRA, Ruy Barbosa. Curso de direito tributário. 10. ed. São Paulo: Saraiva, 1990.

PASOLD, Cesar Luiz. Metodologia da pesquisa jurídica: teoria e prática. 14 ed. rev. atual. e ampl. Florianópolis: Empório Modara, 2018.

PAULSEN, Leandro. Curso de direito tributário completo. 10. ed. São Paulo: Saraiva Educação, 2019.

SCHOUERI. Luis Eduardo. Direito tributário. 9. ed. São Paulo: Saraiva Educação, 2019. 